\title{
Psychometric properties of the Swedish Diabetes Empowerment Scale
}

\author{
Janeth Leksell ${ }^{1,3}$ RN, PhD, Martha Funnell ${ }^{2}$ MS, Gun Sandberg ${ }^{1,3}$ DH, PhD, Bibbi Smide ${ }^{1}$ PhD, \\ Gunnel Wiklund ${ }^{1}$ RN (PhD Student) and Karin Wikblad ${ }^{1}$ (Professor) \\ ${ }^{1}$ Department of Medical Sciences, Uppsala University, Uppsala, Sweden, ${ }^{2}$ Michigan Diabetes Research and Training Center, University of \\ Michigan, Medical School, Ann Arbor, MI, USA and ${ }^{3}$ Department of Health and Social Sciences, Högskolan Dalarna, Falun, Sweden
}

Scand J Caring Sci; 2007; 21; 247-252

\section{Psychometric properties of the Swedish Diabetes Empowerment Scale}

Objective: This study was conducted to determine the psychometric properties of the Swedish version of the Diabetes Empowerment Scale (Swe-DES-23).

Research design and methods: A convenience sample of 195 patients with type 1 and type 2 diabetes completed the SweDES-23 questionnaire. To establish discriminant validity, Swe-DES subscales were compared with the Semantic Differential in Diabetes scale (SDD) and a general health scale (EVGFP). Construct validity was tested using factor analyses. To determine unidimensionality of the subscales, interitem correlations were calculated. Internal consistency was tested by the use of the Crohnbach- $\alpha$ coefficient.

Results: The factor analysis resulted in four factors (empowerment subscales) with eigenvalues >1.0, explaining $60 \%$ of the variance. The four empowerment subscales: goal achievement, self-awareness, stress management and readiness to change showed Crohnbach- $\alpha$ values ranging from 0.68 to 0.91 . Patients with good selfreported health and low burden of diabetes scored significantly higher on almost all empowerment subscales. Only weak correlations were found between metabolic control and the empowerment subscales.

Conclusions: The SWE-DES-23 scale had acceptable validity and reliability and, thus, could be a suitable tool in evaluating empowerment-based education programmes. Further testing is needed to shorten the questionnaire.

Keywords: diabetes, empowerment, Diabetes Empower ment Scale, psychometric properties.

Submitted 28 August 2005, Accepted 22 June 2006

\section{Introduction}

The goal of diabetic patient education is to increase patients' ability to use their knowledge and gain the selfefficacy necessary to master daily self-care $(1,2)$. Selfefficacy may be gained through an empowerment approach, which has been defined by Anderson et al. (3) as 'helping people discover and use their innate ability to gain mastery over their diabetes.' The empowerment education performed in diabetes care should consequently be concentrated on these issues. In 1995, Anderson et al. introduced a Diabetes Empowerment programme and, for its evaluation, the Diabetes Empowerment Scale (US-DES) (3).

\section{Correspondence to:}

Janeth Leksell, Högskolan Dalarna, Health and Social Sciences, SE 79188 Falun, Sweden.

E-mail: jle@du.se
The first version of the US-DES was a 37-item questionnaire, which included eight subscales, namely: satisfaction and dissatisfaction related to living with diabetes; identification and achievement of personally meaningful goals; application of systematic problem-solving process; coping with emotional aspects of living with diabetes; stress management; appropriate social support; self-motivating; and cost/benefit decisions regarding behaviour changes (3). The evaluation of this first version of US-DES showed that only three of the eight subscales had internal consistency $\geq 0.80$, thus the authors reduced the questionnaire from 37 to 28 items. Evaluation of the latter included three subscales, which showed good evidence for reliability and validity. The three subscales were: managing psychosocial aspects of diabetes; assessing dissatisfaction and readiness to change; and achieving diabetes goals (4).

The US-DES scale has recently been translated into a Chinese version measuring five separate domains with 20 items. The psychometric analysis supported the validity and reliability of the Chinese version (5).

To evaluate our Swedish empowerment education programmes, we need a Swedish DES version. Thus, the aim 
of the current study was to determine the psychometric properties of the Swedish version of the Diabetes Empowerment Scale.

\section{Research design and methods}

\section{Translation and development of the Swedish version of the DES}

The American pilot version of US-DES-37 (3) was translated into Swedish by a diabetes psychologist. An authorized translator performed the re-translation into American English. This Swedish pilot version was tested in a convenience sample of patients with diabetes. A factor analysis of this early version resulted in 10 factors with eigenvalues $>1.0$, and on the basis of this factor analysis, we reduced the number of items, shortening the questionnaire to 23 items (SWE-DES-23). This testing was done in 1999 before the validity testing of the American version was published, presenting the 28-item DES. We then tested the 28-item DES in a new factor analysis, but found that our Swe-DES23 was more valid than the 28 -item version and made more sense in the Swedish language. In this study, we investigate the psychometric properties of the Swe-DES-23.

The original US-DES as well as Swe-DES-23 uses fivepoint Likert scales ranging from strongly disagree (1) to strongly agree (5). All items have been scored so that a higher value indicates stronger empowerment. All 23 items are presented in Table 2 .

\section{Subjects}

For testing the Swe-DES-23, a convenience sample of 195 diabetic patients at diabetes centres in central Sweden was recruited (Table 1). Twenty-five per cent of them had type 1 diabetes, $25 \%$ had insulin-treated type 2 diabetes and $50 \%$ were patients with type 2 diabetes not treated using insulin. The patients' mean age was 59.4 years and ranged from 22 to 90 years. Duration of diabetes ranged from 1 to 52 years. Written information was sent to the patients together with the questionnaire. Participation was voluntary and the Research Ethics Committee at Uppsala University approved the study design (00-155).

\section{Measurements}

In addition to Swe-DES-23, the following instruments were used: Burden of diabetes was measured using Semantic Differential in Diabetes (SDD). This instrument was developed in 1990 (6) and has since been used as a clinical tool for assessing the burden of diabetes. SDD is composed of seven-point bipolar scales with the following nine adjective pairs: constrained-free, weak-strong, dominant-submissive, worthless-valuable, difficult-easy, unsafe-safe, tense-relaxed, monotonous-varied and independent-dependent. The nine scales may be used either as
Table 1 Demographic and diabetes-related characteristics in patients who completed the Swedish version of the Diabetes Empowerment Scale $(n=195)$

\begin{tabular}{lc}
\hline Characteristics & Patients $(n=195)$ \\
\hline Male (\%) & 51.6 \\
Age (years; mean \pm SD) & $59.4 \pm 12.7$ \\
Years since diabetes diagnosis & $12.9 \pm 12.1$ \\
Diabetes treatment (\%) & \\
Diet only & 18.0 \\
Oral treatment & 32.3 \\
Oral and insulin & 15.9 \\
Insulin & 33.8 \\
Presence of diabetic late complications (\%) & 30.7 \\
HbA1c (\%; mean \pm SD) & $6.7 \pm 1.1$ \\
Education (\%) & \\
Compulsory & 28.1 \\
Upper secondary & 9.2 \\
High school & 42.9 \\
University & 19.8 \\
Cohabitation (\%) & \\
Single living & 27.0 \\
Living with partner & 73.0 \\
Economy (\%) & \\
Good & 42.6 \\
Neither good nor poor & 47.6 \\
Poor & 9.8 \\
Social status (2-8) & $4.9 \pm 1.5$ \\
\hline
\end{tabular}

single scales or be summed into a composed 'burden scale' ranging from 1 (=high burden) to 7 (=low burden). The SDD has been found to be a reliable and sensitive tool for measuring burden of diabetes. The Cronbach- $\alpha$ coefficient in the current study was 0.90 .

Self-perceived health was measured using a single EVGFP scale. (In general, my health is excellent-very good-goodfair-poor). Social status of patients was estimated using a combined score (range: 2-8) considering educational level (primary school $=1$; university $=4$ ) and income (poor economy $=1$; very good economy $=4$ ). Higher figures indicate higher social status, i.e. higher education and higher income.

Diabetes-related data (duration of diabetes, treatment, presence of late complications and current HbAlc value) were collected from the patients' medical records after informed consent from the patients.

\section{Statistics}

Data are presented as mean \pm SD unless indicated otherwise. All analyses were performed with Statistical Package for the Social Sciences (SPSS). Exploratory factor analyses (principal components) were performed to derive independent subscales of the 23 items included in the Swe-DES-23. 
The analysis of score distribution included floor and ceiling effects, i.e. percentage of subjects achieving either the lowest score $(1=$ floor $)$ or the highest score $(5=$ ceiling). For further analysis of score distribution, the response alternatives were also dichotomized into worst (scoring 1-3) and best scores (scoring 4-5), as suggested by Jerard (7).

To determine internal consistency, Cronbach's $\boldsymbol{\alpha}$-coefficients were calculated and inter-item correlations were identified using Pearson's product-moment correlation coefficient. Analysis of variance (ANOva) and Student's $t$-tests were performed to elucidate discriminant validity.

\section{Results}

\section{Construct validity}

The data were analysed by means of an unforced principal component analysis and varimax rotation. The first eight factors had eigenvalues above 1.0, but two of the factors were single-item factors and two included only two items each. Because the original American version of the 28-item DES yielded three factors (4), we tried a threefactor extraction model, but experienced problems in interpreting the factors because of several double loadings.
For that reason, a four-factor model was tested and found to be reasonable (Table 2). The final four factors explained $59.8 \%$ of the variance and all four factors had eigenvalues higher than 1 (Table 3).

Factor 1: Goal achievement and overcoming barriers for goal achievement included 10 items, all dealing with setting and achieving diabetes goals, motivation and how to overcome barriers to achieving diabetes goals.

Factor 2: Self-awareness included four items about selfknowledge, knowledge of how to make the necessary selfcare choices and awareness of how to obtain support if needed.

Factor 3: Managing stress included four items about positive and negative coping with diabetes-related stress.

Factor 4: Assessing dissatisfaction and readiness to change included five items covering what parts of taking care of diabetes the respondent was dissatisfied with and what he or she was ready to change.

\section{Score distribution, internal consistency and inter-item correlations}

Almost the full range of score distributions was observed in the empowerment subscales. The percentage of subjects scoring at the floor was $<0.5 \%$. The highest

Table 2 Factor loadings for the four extracted factors after varimax rotation $(n=195)$

\begin{tabular}{|c|c|c|c|c|}
\hline Factors and items & Factor 1 & Factor 2 & Factor 3 & Factor 4 \\
\hline \multicolumn{5}{|l|}{ Factor 1: Goal achievement and overcoming barriers to goal achievement ( $\alpha=0.91)$} \\
\hline Choosing realistic diabetes goals & 0.67 & -0.02 & 0.22 & 0.16 \\
\hline Reaching diabetes goals & 0.72 & 0.08 & 0.15 & 0.22 \\
\hline Turning goals into a workable plan & 0.83 & 0.09 & 0.13 & 0.08 \\
\hline Overcoming barriers to reaching goals & 0.80 & 0.16 & 0.12 & 0.11 \\
\hline Try out different ways of overcoming barriers & 0.75 & 0.02 & 0.01 & 0.15 \\
\hline Best ways of overcoming barriers & 0.76 & 0.24 & 0.04 & 0.25 \\
\hline Support in dealing with diabetes & 0.59 & 0.20 & 0.26 & 0.10 \\
\hline How to stay motivated to care for diabetes & 0.64 & 0.33 & 0.23 & 0.09 \\
\hline How to motivate oneself to care for diabetes & 0.69 & 0.30 & 0.32 & -0.10 \\
\hline Is it worth my while to change how to take care of diabetes & 0.52 & 0.09 & 0.38 & 0.07 \\
\hline \multicolumn{5}{|l|}{ Factor 2: Self-awareness $(\alpha=0.80)$} \\
\hline Where to get support for caring for diabetes & 0.06 & 0.88 & 0.02 & 0.07 \\
\hline Asking for support for caring for diabetes when needed & 0.12 & 0.88 & 0.04 & 0.11 \\
\hline Knowing enough for making self-care choices & 0.35 & 0.55 & 0.17 & 0.27 \\
\hline Knowing enough about oneself as a person to make diabetes care choices & 0.37 & 0.57 & 0.25 & 0.15 \\
\hline \multicolumn{5}{|l|}{ Factor 3: Managing stress $(\alpha=0.80)$} \\
\hline Ways that having diabetes causes stress in life & -0.05 & -0.15 & 0.66 & 0.33 \\
\hline Positive ways of coping with diabetes-related stress & 0.30 & 0.22 & 0.78 & 0.05 \\
\hline Negative ways of coping with diabetes-related stress & 0.31 & 0.03 & 0.74 & 0.25 \\
\hline Coping well with diabetes-related stress & 0.37 & 0.34 & 0.70 & 0.01 \\
\hline \multicolumn{5}{|l|}{ Factor 4: Assessing dissatisfaction and readiness to change $(\alpha=0.68)$} \\
\hline Part of self-care that causes dissatisfaction & 0.16 & -0.03 & 0.02 & 0.60 \\
\hline Parts of self-care that are ready to change & 0.03 & 0.09 & 0.21 & 0.57 \\
\hline Parts that are not ready to change & 0.02 & 0.21 & 0.10 & 0.62 \\
\hline What helps in reaching diabetes goals & 0.41 & 0.13 & 0.11 & 0.52 \\
\hline Barriers that make reaching diabetes goals more difficult & 0.24 & 0.08 & 0.08 & 0.65 \\
\hline
\end{tabular}


Table 3 Descriptive statistics for Swe-DES-23 subscales

\begin{tabular}{lcccc}
\hline Subscale & No. of items & Mean \pm SD & Eigenvalue & Cumulative \% \\
\hline 1. Goal achievement & 10 & $3.64 \pm 0.68$ & 8.4 & 36.4 \\
2. Self-awareness & 4 & $3.98 \pm 0.76$ & 1.9 & 8.2 \\
3. Managing stress & 4 & $3.35 \pm 0.74$ & 1.8 & 7.8 \\
4. Readiness to change & 5 & $3.77 \pm 0.57$ & 1.5 & 5.5 \\
\hline
\end{tabular}

$\mathrm{n}=195$, total scale mean value $(\mathrm{SD})=3.68(0.53)$.

ceiling effect was found in the subscale self-awareness (Table 4).

Cronbach's alpha was calculated to determine internal consistency. The $\alpha$-coefficient for the total score was 0.91 and varied between 0.91 and 0.68 for the four subscales (Table 2).

To determine the unidimensionality of the scales, interitem correlations were also calculated. All inter-item correlations were significant at the $\mathrm{p}<0.0001$ level, except for one double-loading item in factor $4(p<0.03)$. The correlations in factor 1 varied between 0.33 and 0.72 with a mean value of 0.51 . The corresponding figures for factors 2,3 and 4 were respectively: 0.50 (0.38-0.85), 0.51 (0.27$0.74)$ and $0.29(0.16-0.53)$.

\section{Discriminant validity}

The single item on self-perceived health (EVGFP scale) and the nine items in SDD were used to estimate discriminant validity. It was hypothesized that patients with high scores on the empowerment subscales were those who also reported good health. Furthermore, we hypothesized that patients who experienced low burden of diabetes also had high scores on the empowerment subscales.

It was found that patients with good self-reported health scored higher on all empowerment subscales except for the subscale readiness to change. The same pattern was found in this subscale too, but the difference did not reach significance (Table 5). Patients who scored low on burden of diabetes also scored significantly higher on the empowerment subscales (Table 6).

We further hypothesized that patients with good metabolic control and freedom from late complications were more empowered than those who had poor control and presence of late complications. We found only weak correlations between metabolic control and the empowerment subscales. The only correlation with presence of late complications was found for the subscale goal achievement. Patients without late complications reported finding it easier to overcome barriers to goal achievement than did those who already had late complications (Table 7). Duration of diabetes showed a weak but significant correlation

\begin{tabular}{llllll}
\hline \multicolumn{7}{c}{ Empowerment scales } \\
\cline { 2 - 6 } & $\begin{array}{l}\text { Goal } \\
\text { achievement }\end{array}$ & $\begin{array}{l}\text { Self- } \\
\text { awareness }\end{array}$ & $\begin{array}{l}\text { Managing } \\
\text { stress }\end{array}$ & $\begin{array}{l}\text { Readiness to } \\
\text { change }\end{array}$ & $\begin{array}{l}\text { Total } \\
\text { DES }\end{array}$ \\
\hline Worst result (\% scoring 1-3) & 60.3 & 38.1 & 73.4 & 56.6 & 67.7 \\
Best result (\% scoring 4-5) & 39.7 & 61.9 & 26.6 & 43.4 & 32.3 \\
Floor effect (\% scoring 1) & 0.5 & 0.0 & 0.0 & 0.0 & 0.0 \\
Ceiling effect (\% scoring 5) & 3.6 & 12.3 & 3.6 & 4.1 & 1.5 \\
\hline
\end{tabular}

Table 4 Score distributions for Swe-DES-23 total scale and subscales

\begin{tabular}{lllll}
\hline $\begin{array}{l}\text { Self-rated } \\
\text { health }\end{array}$ & $\begin{array}{l}\text { Goal } \\
\text { achievement }\end{array}$ & Self-awareness & $\begin{array}{l}\text { Managing } \\
\text { stress }\end{array}$ & $\begin{array}{l}\text { Readiness to } \\
\text { change }\end{array}$ \\
\hline Excellent & $4.2 \pm 0.9$ & $4.6 \pm 0.55$ & $4.2 \pm 0.84$ & $4.1 \pm 0.92$ \\
Very good & $3.9 \pm 0.6$ & $4.1 \pm 0.73$ & $3.5 \pm 0.68$ & $3.9 \pm 0.50$ \\
Good & $3.7 \pm 0.6$ & $4.0 \pm 0.71$ & $3.4 \pm 0.71$ & $3.8 \pm 0.51$ \\
Fair & $3.5 \pm 0.7$ & $4.0 \pm 0.77$ & $3.2 \pm 0.75$ & $3.8 \pm 0.63$ \\
Poor & $3.1 \pm 0.4$ & $3.4 \pm 1.00$ & $2.9 \pm 0.70$ & $3.5 \pm 0.56$ \\
ANOVA tests & $\mathrm{F}=6.98$, & $\mathrm{F}=2.86$, & $\mathrm{F}=3.79$, & $\mathrm{F}=1.74$, \\
& $\mathrm{p}=0.0001$ & $\mathrm{p}=0.02$ & $\mathrm{p}=0.006$ & $\mathrm{p}=0.14$ \\
\hline
\end{tabular}

Table 5 Empowerment scales ratings in relation to self-reported health in 195 diabetic patients 
Table 6 Correlation between burden of diabetes and empowerment

\begin{tabular}{llllll}
\hline Burden of diabetes & $\begin{array}{l}\text { Goal } \\
\text { achievement }\end{array}$ & $\begin{array}{l}\text { Self- } \\
\text { awareness }\end{array}$ & $\begin{array}{l}\text { Managing } \\
\text { stress }\end{array}$ & $\begin{array}{l}\text { Readiness to } \\
\text { change }\end{array}$ & $\begin{array}{l}\text { Total score } \\
\text { Swe-DES-23 }\end{array}$ \\
\hline Constrained-free & $0.31^{* *}$ & $0.37^{* * *}$ & $0.23^{*}$ & $0.32^{* *}$ & $0.41^{* * *}$ \\
Weak-strong & $0.50^{* * *}$ & $0.54^{* * *}$ & $0.21^{*}$ & $0.23^{*}$ & $0.52^{* * *}$ \\
Dominant-submissive & $0.41^{* * *}$ & $0.41^{* * *}$ & $0.29^{* *}$ & $0.23^{*}$ & $0.46^{* * *}$ \\
Worthless-valuable & $0.34^{* * *}$ & $0.45^{* * *}$ & $0.35^{* * *}$ & $0.28^{* *}$ & $0.49^{* * *}$ \\
Difficult-easy & $0.34^{* * *}$ & $0.42^{* * *}$ & $0.23^{*}$ & 0.19 & $0.40^{* * *}$ \\
Unsafe-safe & $0.32^{* * *}$ & $0.42^{* * *}$ & $0.22^{*}$ & 0.16 & $0.38^{* * *}$ \\
Tense-relaxed & $0.47^{* * *}$ & $0.57^{* * *}$ & $0.24^{*}$ & $0.24^{*}$ & $0.52^{* * *}$ \\
Monotonous-varied & $0.53^{* * *}$ & $0.41^{* * *}$ & $0.22^{*}$ & $0.24^{*}$ & $0.47^{* * *}$ \\
Independent-dependent & $0.36^{* * *}$ & $0.56^{* * *}$ & $0.30^{* *}$ & $0.32^{* *}$ & $0.53^{* * *}$ \\
\hline
\end{tabular}

${ }^{*} p<0.01,{ }^{*} p<0.001,{ }^{* * *} p<0.0001$; high figure on Burden of Diabetes scale indicates low burden. High figure on Swe-DES-23 means more empowered.
Table 7 Correlations between Swe-DES-23 and diabetes-related data

\begin{tabular}{llll}
\hline & $\begin{array}{l}\text { Diabetes } \\
\text { duration }\end{array}$ & HbA1c & $\begin{array}{l}\text { Late } \\
\text { complications }\end{array}$ \\
\hline Goal achievement & -0.11 & -0.15 & $-0.15^{*}$ \\
Self-awareness & -0.12 & -0.14 & -0.01 \\
Managing stress & -0.13 & -0.08 & -0.11 \\
Readiness to change & -0.07 & -0.03 & -0.06 \\
Total & $-0.15^{*}$ & -0.13 & -0.11 \\
\hline
\end{tabular}

${ }^{*} p<0.05$

with the total DES, meaning that patients with short duration of illness scored higher on the total empowerment scale.

It could also be hypothesized that patients with good income and higher level of education feel themselves to be more empowered than do those with lower education level and lower income. The only significant correlation we found was between social status and readiness to change $(\mathrm{r}=0.18, \mathrm{p}<0.05)$.

\section{Conclusions}

The results from testing the SWE-DES-23 were promising. However, the factor analysis showed a discrepancy between the US and Swedish versions, in that the US version yielded three and the Swedish version four subscales. However, the alpha values for the four subscales and the total SWE-DES-23 scale were acceptable. The difference was that the US subscale 'Managing the Psychosocial Aspects of Diabetes' was divided into two subscales in the Swedish version: 'Self-awareness' and 'Managing stress'. One problem when comparing translated instruments is that of achieving linguistic and cultural equivalence (8). We consider the semantic equivalence to be acceptable, as we used authorized translators for the back translation. We have not tested the conceptual equivalence, but the intention has been to use the same theoretical empowerment construct as in the original US version (4).

Interestingly, the recently published Chinese version of the DES 20-item scale yielded five subscales with alpha values ranging from 0.76 to 0.89 (5). The five subscales were consistent with the SWE-DES-23 subscales, with the exception of the subscale 'obtaining support'. In the SWEDES, the support items were included in the self-awareness subscale. This discrepancy between the outcomes of factor analysis in the three countries requires further investigation.

The DES scale had acceptable internal consistency and inter-item correlations. Both floor and ceiling effects were relatively small. High ceiling effects are problematic when evaluating nursing interventions. In subjects scoring high already in the pretest it is impossible to show improvements. The highest proportion of ceiling effect was found in the self-awareness subscale $(12.3 \%)$. This can be compared with the widely used SF 36 questionnaire showing proportionate ceiling effects up to $72.2 \%$ (9). When looking at the results from the scoring worst/best analysis it can be concluded that the range from $26.6 \%$ to $73.4 \%$ must be classified as satisfactory. According to Jerard (7) the proportion should range from $30 \%$ to $80 \%$.

To determine discriminant validity, we formulated four hypotheses. The first assumed that patients reporting good health also had high scores on the Swe-DES-23 scale. This could be confirmed with one exception, namely the subscale 'readiness to change'. This is not surprising, as patients who perceive that they are in excellent health might consider that they have no need to change or that they have made all the changes they are able and willing to make. In contrast, those who perceive that they are in poor health might not feel ready because of feelings of hopelessness, lack of self-efficacy or a belief that the changes will not improve their health. Corrigan et al. also found a significant association between empowerment and quality of life (10). The EVGFP scale was chosen as it measures the patient's own perceived health and gives information about the 
person's own experience of health; also it does not consider whether the person has a chronic disease (11).

The second hypothesis could also be confirmed, as patients who experienced the burden of diabetes to be low had significantly higher scores on the Swe-DES-23 scale. An empowered patient probably has the knowledge, skills and attitudes needed to manage diabetes treatment and self-care without experiencing too much burden.

The third hypothesis that patients with good metabolic control were more empowered than those with poor control could not quite be confirmed, as our analysis showed only a weak correlation. This is in accordance with a study by Via and Salvyer (12), wherein no significant correlations were found between $\mathrm{HbA}_{1 \mathrm{c}}$ and the US DES37 version. Moreover, in the Chinese version only a weak correlation was found between the global scale and HbAlc of patients with type 2 diabetes. In another study (13), it was found that patients with acceptable metabolic control were those who experienced the highest quality of life, while those with good or poor quality of life reported lower scores, which may explain the present findings. Patients without late complications found it easier to overcome barriers to goal achievement than did those who had late complications. In another study, we found that patients with late complications perceived problems with selfmanagement. Perceived problems were difficulties with insulin treatment and unstable blood glucose, situations requiring complex self-management (14). In the light of this finding, it is easy to understand and explain why these individuals' goal is not easy to attain.

The last hypothesis concerned social status (economy and education). Social status seemed to influence patients' readiness to change, such that people with high education levels and good personal economy were prepared to change and able to assess dissatisfaction. No other significant correlations were found between social status and the empowerment subscales, thus our fourth hypothesis could not fully be verified.

Our overall conclusion is that the current Swe-DES-23 scale possesses acceptable validity and reliability. This confirms its utility in measuring empowerment-based education programmes, although the different subscales must be further developed and the questionnaire needs to be shortened for clinical use.

\section{Author contributions}

All authors contributed to the writing of this manuscript. Karin Wikblad, Janeth Leksell, Bibbi Smide and Gun Sandberg collected the data. Karin Wikblad, Bibbi Smide, Gunnel Wiklund and Janeth Leksell completed the statistical analyses. All authors, bedsides Gun Sandberg, participated in study conception and design. Finally, all authors took part in the critical revision of the manuscript.

\section{Funding}

Financial support was obtained from the Swedish Diabetes Association. The study was also in part supported by grant number NIH5P60 DK20572 and 1 R18 0K062323-01 from the National Institute of Diabetes $\&$ Digestive $\delta$ Kidney Diseases, USA.

\section{References}

1 Van Dam HA, Van der Horst FG, Van den Borne B, Ryckman $\mathrm{R}$, Crebolder H. Provider-patient interaction in diabetes care: effects on patient self-care and outcomes. A systematic review. Patient Couns 2003; 51: 17-28.

2 Funnell M, Anderson R. Working toward the next generation of diabetes self-management education. Am J Prev Med 2002; 22: 3-5.

3 Anderson R, Arnold M, Funnell M, Fitzgerald J, Butler P, Feste C. Patient empowerment Results of a randomized controlled trial. Diabetes Care 1995; 18: 943-9.

4 Anderson R, Fitzgerald J, Funnell M, Marrero D. The diabetes empowerment scale: a measure of psychosocial selfefficacy. Diabetes Care 2000; 23: 739-43.

5 Shiu A, Wong R, Thompson D. Development of a reliable and valid Chinese version of the diabetes empowerment scale. Diabetes Care 2003; 26: 2817-21.

6 Wikblad K, Wibell L, Montin K. The patient's experience of diabetes and its treatment: construction of an attitude scale by a semantic differential technique. $J$ Adv Nurs 1990; 15: 1083-91.

7 Jerard K. Basic item analysis for multiple-choice tests. Pract Assess Res Eval 1995; 4. http://PAREonline.net/getvn.asp? $\mathrm{v}=48 \mathrm{n}=10$ (last accessed 14 April 2006).

8 Beck C, Bernal H, Froman R. Methods to document semantic equivalence of a translated scale. Res Nurs Health 2003; 26: 64-73.

9 Sullivan M, Karlsson J, Ware J Jr. The Swedish SF-36 health survey - I. Evaluation of data quality, scaling assumptions, reliability and construct validity across general populations in Sweden. Soc Sci Med 1995; 41: 1349-58.

10 Corrigan P, Faber D, Rashid F, Leary M. The construct validity of empowerment among consumers of mental health services. Schizophr Res 1999; 38: 77-84.

11 Ware J, Snow K, Kosinski M, Gandek B. SF-36 Health Survey: Manual and Interpretation Guide. 1993, The Health Institute, New England Medical Centre, Boston, MA.

12 Via P, Salyer J. Psychosocial self-efficacy and personal characteristics of veterans attending a diabetes education program. Diabetes Educ 1999; 25: 727-37.

13 Wikblad K, Leksell J, Wibell L. Health-related quality of life in relation to metabolic control and late complications in patients with insulin dependent diabetes mellitus. Qual Life Res 1996; 5: 123-30.

14 Leksell J, Sandberg G, Wikblad K. Self-perceived health and self-care among diabetic subject with defective vision: a comparison between subjects with threat of blindness and blind subjects. J Diabetes Complicat 2005; 19: 54-59. 